\title{
ESTUDIOS CULTURALES/CRÍTICA LITERARIA: ¿UNA CONTRADICCIÓN INSUPERABLE?*
}

\author{
CULTURAL STUDIES/CRITICAL LITERARY: \\ AN INSUPERABLE CONTRADICTION?
}

\author{
Alfredo Laverde Ospina \\ Universidad de Antioquia. Medellín, Colombia \\ alfredolavo2@yahoo.es
}

\begin{abstract}
Resumen: Este trabajo se propone tratar sobre la aparente contradicción entre los estudios culturales y la crítica literaria, a propósito de un texto de Beatriz Sarlo y dos, considerados en este caso respuestas, de Mabel Moraña. La lectura propuesta de estos documentos permite considerar la función crítica de los estudios literarios y, por consiguiente, la recuperación del "valor estético" en cuanto categoría no precisamente excluyente ni hegemónica, sino como una elaboración simbólica cultural que dice de las polémicas ético ideológicas de los grupos sociales y del continente latinoamericano en general.
\end{abstract}

Palabras clave: Estudios culturales, crítica literaria, valor estético, América Latina.

\begin{abstract}
This study intends to discuss the apparent contradiction between cultural studies and literary criticism, with regard to a text by Beatriz Sarlo and two, in this case considered responses, Mabel Moraña. The proposed reading of these documents allows to consider the critical role of literary studies and, consequently, the recovery of the "aesthetic value" does not exactly exclusive or hegemonic category, but as a symbolic cultural development which tells of the controversial ideological ethics of social groups and of Latin America in general.
\end{abstract}

Keywords: Cultural studies, literary criticism, esthetic value, Latin America.

Recibido: 27.04.2014. Aceptado: 01.09.2014.

* Este artículo es resultado parcial del proyecto de investigación "La historia de la literatura de América Latina: proyecto intelectual en el contexto de los estudios culturales" aprobado por el Comité de Investigación Universitaria de la Universidad de Antioquia (2012-2015) y dirigido por Alfredo Laverde Ospina. 
Lo estético, por tanto, es sencillamente el nombre que se da a esa forma híbrida de conocimiento que puede clarificar la materia prima de la percepción y la práctica histórica, revelando la estructura interna de lo concreto.

Terry Eagleton (2006: 69).

\section{Los estudios culturales y la crítica literaria}

$\mathrm{E}^{\mathrm{s}}$ N SU ARTículo titulado "Althusser, los estudios culturales y el concepto de ideología” (2008), el filósofo colombiano Santiago Castro-Gómez al referirse a la crisis actual de los estudios culturales, debido al sometimiento de la cultura a los imperativos del mercado, menciona como peligroso el alejamiento progresivo de estos de la teoría crítica marxista. A modo de contraste, retoma lo planteado por Stuart Hall en relación con la identificación de dos épocas claramente delimitadas por la influencia de Althusser.

Es así como durante la década del setenta, liderada por Stuart Hall, se efectúa un diálogo creativo con la "teoría social más avanzada de su tiempo: el estructuralismo" y que significó para la escuela inglesa el salto del paradigma humanista, o culturalista, inspirado por los estudios literarios (Hoggart, Thompson y Williams), al paradigma estructuralista sustentado por el psicoanálisis, la antropología, la lingüística y la teoría social marxista.

De acuerdo con Castro-Gómez, la importancia de la influencia de Althusser en los estudios culturales se centra en el papel que pasó a ocupar el concepto de ideología en calidad de categoría analítica y que le permitió, al conjunto de los investigadores de la Escuela de Birmingham plantearse el problema de las formas y los procesos culturales como creadores y portadores de significados, junto con su difusión en las sociedades actuales. $\mathrm{Al}$ respecto, Stuart Hall en el artículo aludido arriba, "Estudios culturales: dos paradigmas" (1994), explica en detalle el giro efectuado en los estudios culturales entre los dos paradigmas mencionados: "culturalista" y "estructuralista"

${ }^{1}$ De acuerdo con Hall (1994): "La veta 'culturalista' en los estudios culturales fue interrumpida por la llegada a la escena intelectual de los 'estructuralismos'. Estos, posiblemente más variados que los 'culturalismos', compartían empero ciertas posiciones y orientaciones que permiten agruparlos bajo una sola denominación sin dema- 
En este mismo sentido, en el Diccionario de teoría crítica y estudios culturales, dirigido por Michel Payne, bajo el término 'Estudios culturales', Michel Green afirma que: "Diversas formas de marxismo, con especial acento en las divisiones de clase, el Estado, la dominación y el mecanismo de la IDEOLOGÍA, constituyeron la base de importantes estudios [...]" (2008: 204). Sin embargo, en la actualidad, los estudios culturales pasan por lo que Castro-Gómez denomina una tercera etapa, más "light", en la que el distanciamiento de la teoría crítica ha significado la disolución política de los estudios culturales y, en consecuencia, la exclusión del análisis ideológico y la consiguiente incursión en una "neutralidad" que raya en la complicidad, cayendo en lo que Douglas Kellner, citado por Castro-Gómez, denomina "populismo cultural que celebra los supuestos efectos 'democratizadores' de la sociedad de consumo" 2 .

Esta última etapa ha sido denominada por la crítica literaria chilena Nelly Richard como la institucionalización de los estudios culturales, según un modelo globalizado instalado en la academia internacional, con una doble orientación: por una parte hacia la cultura popular y, por otra, hacia los estudios postcoloniales y de subalternidad. El aspecto más importante de la perspectiva de Richard se centra en la existencia de una hipotética tercera fase surgida en la década de los noventa, que compete a América Latina, y en la que se efectúan activos debates en torno e, incluso, en contra de los estudios culturales, incluyendo su versión metropolitana. En consecuencia, para la autora, los estudios culturales no pueden ser objeto

siado problema. Se ha comentado que mientras el paradigma 'culturalista' puede ser definido sin necesidad de recurrir a una referencia conceptual al término 'ideología' (evidentemente la palabra aparece, mas no se trata de un concepto clave), las intervenciones 'estructuralistas' han sido en gran medida articuladas en torno al concepto de 'ideología': consecuentemente con su más impecable linaje marxista, el de 'cultura' no figura de manera tan prominente. Pero si esto puede ser cierto para los estructuralistas marxistas, es, por decir lo menos, medio cierto para el esfuerzo estructuralista como tal. Pero ya es un error común condensar a este último exclusivamente en torno al impacto de Althusser y todo lo que ha aparecido en la estela de sus intervenciones, donde 'ideología' ha tenido un papel seminal, pero modulado: y así omitir la importancia de Levi-Strauss, y los semióticos del primer momento, que hicieron la primera ruptura”.

${ }^{2}$ En relación con esta crítica, Mattelart (2004). 
de una definición unitaria, pues en la actualidad cobija a una pluralidad de prácticas (2010)3.

A propósito de la denunciada despolitización de los estudios culturales importados por la academia estadounidense de la inglesa, existen dos explicaciones que, en conjunto parecen ser plausibles. De acuerdo con Walter Mignolo, los estudios culturales llegan a los Estados Unidos a insertarse en los proyectos intelectuales y académicos de género y sexualidad, por un lado, y de etnicidad y raza, por otro, tan sólo desde 1983, como efecto del éxito que tuvieron en Europa. Es decir, su importancia se explica sobre la base de una razón institucional, sin contar que los estudios culturales en la academia estadounidense se inscriben en las ciencias humanas, mientras que los estudios latinoamericanos de área, tradicionalmente, se han inscrito en las ciencias sociales (2003) .

Si retomamos lo planteado por Castro-Gómez, la inscripción de los estudios culturales en los estudios literarios y la filosofía, junto con sus metodologías de tradición humanista (2003), se obtiene como consecuencia el que el estatuto de mercancía de los productos culturales no haya sido objeto de un distanciamiento crítico. En general, no existe una evaluación de dichos productos ni en términos estéticos, ni ideológicos ni políticos. Se está ignorando el principio básico emanado de la segunda etapa de los estudios culturales, en el contexto de la teoría crítica o "etapa althusseriana" para la cual la cultura es un producto anclado en "aparatos" institucionales $\mathrm{y}$, en consecuencia, la sociedad es concebida como una red de antagonismos en las que dichas instituciones (Estado, familia, escuela, medios de comunicación, etc.) se constituyen en verdaderos mecanismos de control:

${ }^{3}$ De acuerdo con la autora: "Lo que agrupa la actual nomenclatura 'Estudios Culturales' [...] no designa un campo homogéneo de aplicaciones, al menos en América Latina, sino un conjunto plural de prácticas cuyo significado y posición -en lo teórico, en lo crítico-disciplinario y en lo político e institucional- varía según sus contextos de inscripción tanto socio-histórica como universitarios" (2010: 68).

4 Walter Mignolo resalta la relación de los estudios culturales sobre América Latina, o como lo prefiere Daniel Mato Latin American Cultural Studies para diferenciarlos de los estudios culturales realizados desde América Latina, con los estudios de área surgidos durante la Guerra Fría (2003). Esta distribución disciplinar o paradigmática de los estudios culturales y los estudios latinoamericanos de área es particularmente significativa para América Latina y para John Beverly cuando se trata de diferenciar los estudios culturales estadounidenses y los del Tercer Mundo (Beverly, 1996). 
[...] el objeto característico de los estudios culturales no es un comentario teórico reforzado por referencias culturales, ni una forma particular de cultura, sino un proceso o momento cultural, analizado con fines determinados y en un lugar y tiempo específicos. La cultura no está localizada en los textos, ni es el resultado de su producción, ni está solamente en los recursos, apropiaciones e innovaciones culturales de los mundos vividos cotidianamente, sino en las diferentes formas de construcción de sentido, dentro de diversas configuraciones, en sociedades incesantemente marcadas por el cambio y el conflicto (Green, 2008: 204-205).

En el contexto latinoamericano, la ausencia de la perspectiva crítica se agudiza si se tiene en cuenta que para Walter Mignolo la importación de los estudios culturales desde la academia estadounidense, bajo ninguna circunstancia debe responder a razones instrumentales o estratégicas, sino estrictamente a razones críticas. El teórico argentino, al mencionar las razones instrumentales alude a "la eficiencia en la producción y en la administración de bienes y servicios, incluida la información entendida como educación", asimismo, las razones estratégicas remiten a la necesidad de obtener ventajas sobre el enemigo: "cómo vencerlo", “cómo sacar ventaja de una situación”, es decir, lo que para los Estados Unidos significaron los estudios de área desde la postguerra. Por el contrario, la razón crítica alude a los proyectos intelectuales que surgen de las condiciones históricas reales, los fines con los cuales se genera el conocimiento o comprensión (2003).

En este mismo sentido, Nelly Richard al hacer referencia a los riesgos de transferencia y reproducción periférica de su modelo, distantes de proyectos propios de la tradición latinoamericana y revestidos con el paquete de lo hegemónico, debido a su institucionalización en los Estados Unidos, parece aceptar que dicha importación borra "la densidad histórica de lo local y de sus regionalismos críticos" (Richard, 2001: 187). Desde esta perspectiva, y de acuerdo con Hugo Achugar en su artículo "Leones, cazadores e historiadores. A propósito de las políticas de la memoria y del conocimiento" (1998: 207-219), Richard enfatiza la crítica del estudioso uruguayo en relación con el silenciamiento de la tradición del ensayismo latinoamericano que, como es sabido por todos, adelantó muchos de los desplazamientos e intercambios disciplinares que, en el contexto actual, se presentan como novedosos. Así las cosas, la profesora chilena señala, citando de nuevo a 
Achugar, cómo se deja de lado toda una memoria y una tradición de lectura e irónicamente se presenta como algo totalmente novedoso y distinto de lo hecho hasta el momento en el continente 5 .

En defensa del campo intelectual latinoamericano y la existencia de una tradición de estudios literarios claramente inscritos en la teoría crítica (sobre la base de los condicionamientos sociales y el sentido común), el Diccionario de estudios culturales latinoamericanos (2009), coordinado por Mónica Szurmuk y Robert McKee Irwin, propugna por el reconocimiento de la inter y transdisciplinariedad en la producción del conocimiento en América Latina y rescata el papel del ensayo como espacio discursivo de reflexión en torno de "las cuestiones de lo nacional y lo continental, lo rural y lo urbano, la tradición contra la modernidad, memoria e identidad, subjetividad y ciudadanía y, especialmente, el papel de los intelectuales y las instituciones en la formación de discursos y de prácticas sociales, culturales y politicas" (2009: 12). También, Grínor Rojo afirma la existencia de una tradición de teoría crítica latinoamericana concretizada en la producción de una conceptualización teórica "[...] desde un contexto de enunciación que, aun manteniendo conexiones con la tradición metropolitana en el mismo sentido, difiere de ella, constituyéndose de ese modo en una corriente paralela con sus propias obligaciones y sus propios hallazgos" (2012: 10). Es decir, coherente con una razón crítica en términos de Mignolo.

Esta sinopsis, por demás incompleta, tiene como finalidad ejemplificar las complejas discusiones académicas que ha provocado la aparente aceptación acrítica de los estudios culturales en el ámbito universitario de América Latina, la defensa de la tradición académica continental y la posterior toma de posición de cada uno de los sectores académicos involucrados. En este sentido, cabría resaltar que la posición más cercana a lo que efectivamente está sucediendo en América Latina define a los estudios culturales como un espacio de articulación de disciplinas que, apesar de sus falencias

${ }^{5}$ En relación con la existencia de los estudios culturales, sus equivalentes, en América Latina, John Beverly afirma el carácter político de los estudios insertos en la teoría de la crítica cultural producidos por los teóricos latinoamericanos. En este sentido, resalta la filiación, o al menos las posibles correlaciones de estos estudios con los estudios subalternos como corriente, resueltamente, política de los estudios culturales (1996). 
(escasa reflexión epistemológica y metodológica) ha impulsado el reconocimiento de otras formas de producción del saber, así como la promoción del sentido común; lo que en resumidas cuentas remite a la teoría crítica y la crítica de la cultura que viene haciéndose en Latinoamérica mucho antes de la aparición de los estudios culturales.

No obstante, no sea posible defender la existencia una absoluta autonomía intelectual, es cierto que el diálogo y las lecturas activas con otras esferas teóricas e intelectuales, han contribuido y deberán seguir haciéndolo en la dilucidación de problemas y soluciones continentales. Asimismo, habría que resaltar lo que para Castro-Gómez es el aporte fundamental de los estudios culturales: el "giro hermenéutico" que "afecta a las disciplinas tradicionales y a los espacios institucionales" (2003: 70) y, en consecuencia, el paso de la teoría tradicional (objetiva) a la teoría crítica. Es decir, esta coyuntura acepta como legítima la situación de la producción de saberes y conocimientos desde antaño trabajados por nuestros intelectuales, científicos sociales, críticos e historiadores de la literatura.

A su vez, Walter Mignolo en defensa de la razón crítica latinoamericana afirma que "los estudios culturales no pueden identificarse con una agenda intelectual, sea esta la de Raymond Williams o la de Stuart Hall, la de Larry Grossberg o de Néstor García Canclini” (53) y paso seguido, tras la pregunta "¿Qué tipo de conocimiento/comprensión nos exige la historia, la sociedad y las genealogías intelectuales en las que elegimos inscribirnos" (51) formula la pregunta en torno a la imposibilidad de evadir un lugar de enunciación que, desde la teoría crítica, debe ser objeto de reflexión: “¿Desde qué perspectiva (disciplinaria, étnica, genérica, sexual, nacional, etc.) produciremos tal conocimiento o comprensión?” (2003: 51).

\subsection{Una polémica emblemática}

En defensa de los estudios literarios de América Latina que históricamente se han constituido en el espacio de expresión de un proyecto intelectual, ya sea dilucidando diversas representaciones literarias del continente, unas de carácter epistemólógico, otras de carácter ontológico, junto con sus tomas de posición política en contra de interpretaciones generalizadoras y excluyentes, es claro que en el contexto de los estudios culturales se puede 
establecer un diálogo fructífero con algunas de las posturas críticas de la teoría poscolonial y los estudios subalternos.

Es el caso de los estudios poscoloniales y el papel de la crítica literaria en cuanto espacio discursivo a partir del cual se revelan las relaciones entre "los textos y las realidades existenciales de la vida humana, la política, las sociedades y los acontecimientos", en términos de Edward Said (2008: 54). Para este teórico, los textos son objetos y productores de circunstancias que se hacen sentir con independencia de cualquiera que fuere el método que el crítico posea: "La cuestión es que los textos tienen modo de existencia que hasta en sus formas más sublimes están siempre enredados por la circunstancia, el tiempo, el lugar y la sociedad; dicho brevemente, están en el mundo y de ahí que sean mundanos" (2008: 54), sin que esto signifique la negación de la existencia de un campo discursivo, semióticamente complejo, denominado literatura que presenta como rasgo diferencial con otros campos un "régimen de representación" que varía no sólo histórica sino cultural e ideológicamente pero que en cualquier caso es la expresión de los grupos humanos de los cuales surge ${ }^{6}$.

Desde esta perspectiva, en su artículo "Los estudios culturales y la crítica literaria en la encrucijada valorativa" 7 (2000), Beatriz Sarlo, frente al desplazamiento de la crítica literaria como resultado de la confusión epistemológica y metodológica efectuada por la llegada sorpresiva de los estudios culturales, y haciendo una aclaración en relación con la diferencia entre los textos de cultura y del arte, sin afirmar pero tampoco negar que estos últimos sean una subespecie de los primeros, se atreve a asegurar que no se debe olvidar que la crítica literaria trata de los valores estéticos y que estos últimos no son patrimonio exclusivo de los críticos conservadores o intelectuales tradicionales, pues esto sería tanto como encomendarles a ellos la función de enfrentar un tema central tanto a la teoría política como a la teoría del arte.

No está de más resaltar que Sarlo es reconocida en el continente no sólo

${ }^{6}$ Son iluminadoras las palabras de Jacques Rancière: "Aquello que el singular del "arte" designa es el recorte de un espacio de presentación por el cual las cosas del arte son identificadas como tales. Y aquello que liga la práctica del arte a la cuestión de lo común es la constitución a la vez material y simbólica, de un cierto espacio-tiempo, de un suspensión en relación con las formas ordinarias de la experiencia sensible" (2011: 32-33).

${ }^{7}$ Publicado inicialmente en Chile en la Revista de Crítica Cultural No 15 de 1997. 
como autora y coautora de diversos textos sobre teoría literaria, ensayos críticos, libros que podrían inscribirse en el ámbito de los estudios culturales, Ensayos argentinos de Sarmiento a la vanguardia (1997) pasando por La imaginación técnica, Escenas de la vida posmoderna. Intelectuales, arte y videocultura en Argentina (1992), así como su trabajo en la revista Punto de vista; sin embargo, esta actividad intelectual no le ha impedido afirmar que la crítica literaria debería ocuparse, como lo ha hecho hasta un pasado muy cercano, de los valores estéticos y las cualidades específicas del texto literario. Esto, indudablemente, está relacionado con el carácter socialmente significativo de un discurso y se pregunta, paso seguido, ¿Cuál es el valor del discurso de la crítica en la sociedad contemporánea?

Es claro para Sarlo que la crítica literaria ocupó un lugar central en la construcción de la esfera pública del continente e incidió en la agenda de políticos e intelectuales, sobre todo en lo relacionado con las literaturas y culturas nacionales. De la misma manera como lo hizo a través de las revistas y diarios de América Latina durante la década del sesenta y comienzos de los setenta, incluidos los aspectos concernientes a los valores estéticos y literarios. Paso seguido, la autora explica lo que denomina "La redención social de la crítica literaria por el análisis de la cultura”. Este último tema, como es de esperarse, está directamente relacionado con la "hegemonía de lo mediático-visual" en un momento en que todavía tenemos aspiraciones en relación con la lecto-escritura como elemento "clave para descifrar a la palabra escrita, incluso cuando esta se ha liberado del papel”. En general, la redención social de la crítica se produjo por el desplazamiento que los estudios culturales efectuaron en aras del análisis cultural, dejando de lado la cuestión del valor ${ }^{8}$.

\footnotetext{
${ }^{8}$ En relación con el valor, adherimos inicialmente a lo planteado por Casanova a partir de Pound para quien en el "universo literario el valor está directamente asociado con la creencia" (2001: 31). "En esta creencia se basa el funcionamiento del universo literario entero: todos los jugadores tienen en común en sus envites una reputación que no todos poseen, o no en el mismo grado, pero por cuya posesión todos van a luchar" (31). Para una aproximación reciente, en relación con América Latina, se debe resaltar el artículo de Françoise Perus "Leer no es consumir. La literatura latinoamericana ante la globalización" (2009). En este artículo la autora hace una defensa de la memoria histórica que respalda las concepciones de la literatura y lo literario y acusa el alejamiento de la tradición letrada y, la consiguiente, legitimación de modalidades de lecturas "consumistas" confinando parte de la literatura en círculos "elitistas" posibilitando la disolución de las formas artísticas y sus herencias históricas (2009).
} 
Es evidente que no se trata de cuestionar la legitimidad de los estudios culturales, sino su imposibilidad de responder a los problemas y preguntas propios de la crítica literaria. De acuerdo con Sarlo, estas preguntas o problemas se pueden sintetizar en: la relación entre la literatura y la dimensión simbólica del mundo social; las cualidades específicas del discurso literario sin reducirlo a una cuestión institucional y el diálogo entre textos literarios $\mathrm{y}$ textos sociales.

En consecuencia, para la autora argentina, los valores estéticos no se pueden dejar a la deriva, pues, es evidente que son los problemas que le conciernen a la crítica literaria. En este sentido, destaca la necesidad de replantearse el problema de los valores en el contexto de la cultura contemporánea y, sobre todo, reitera que la "literatura es socialmente significativa porque algo, que captamos con dificultad, se queda en los libros y puede volver a activarse una vez que éstos han agotado otras funciones sociales"9.

Por último, enfatiza en la necesidad de "imaginar nuevos modos de considerar los valores" y por ello acude a la perspectiva relativista a partir de la cual éstos varían según los contextos culturales sin desconocer que la discusión de dichos valores es siempre una "discusión textualizada". La relatividad de los valores no implica indiferencia y "para cada cultura los

${ }^{9}$ Es claro que ese algo, que se queda en los libros está directamente relacionado con la mundaneidad defendida por Edward Said. En relación con esto, John Kraniauskas (2000: 241) en la transcripción de un encuentro realizado en Florianópolis (Brasil) titulado "Literatura y valor" (Beatriz Sarlo, Roberto Schwarz, John Kraniauskas), en la década de los noventa, en relación con lo planteado por Sarlo, precisa cuatro niveles en relación con el valor: primero resaltando los juicios de valor de las obras individuales y los criterios de valorización: la literatura como valor y procedimiento; en segundo lugar: el valor de lo literario y la cultura como espacio de saberes y haceres autónomos del mercado; tercera acepción: el valor social y normativo de la literatura (en el contexto pedagógico); y, por último, el valor sintomático de la obra literaria: "[...] donde se cifran las formas, los giros y los tonos de una clase social o del conflicto social en un momento histórico dado" (241)). A esta diferenciación, responde Sarlo que en el contexto de los productos que circulan en el mercado la diferencia entre unos y otros se centra en la "organización lingüístico-formal y la organización semántica de esos textos; sin embargo, posteriormente, concede que los valores sobre los cuales se ha centrado han perdido fundamento. No obstante, reitera la importancia de su concepción de la sociedad en conflicto de voces, lo que a la postre nos permitirá retomar el "valor sintomático" de la obra literaria como una concepción estético-literaria en la que tanto la práctica social como su consiguiente configuración textual no sólo semántica sino lingüístico-textual, necesariamente, se constituyen en los determinantes de las diversas "concretizaciones" de la obra literaria. 
valores no son relativos desde un punto de vista intratextual". Así las cosas, los estudios culturales no pueden hacer oídos sordos a la cuestión de los valores.

Para terminar, afirma:

La cuestión estética no es muy popular entre los analistas culturales, porque el análisis cultural es fuertemente relativista y ha heredado el punto de vista relativista de la sociología de la cultura y de los estudios de cultura popular. Sin embargo, la cuestión estética no puede ser ignorada sin que se pierda algo significativo. Porque si ignoramos la cuestión estética estaríamos perdiendo el objeto que los estudios culturales están tratando de construir (como objeto diferente de la cultura en términos antropológicos). Si existe un objeto de los estudios culturales es la cultura definida de un modo diferente a la definición antropológica clásica. Es importante recordar (escribió Hannah Arendt) que el arte y la cultura no son lo mismo (2000: 239).

Siete años después, 2004, Mabel Moraña en su libro Crítica impura. Estudios de literatura y cultura latinoamericana, específicamente, en "Crítica literaria y globalización cultural" y "Literatura, subjetividad y estudios culturales", enfrenta el problema de la "crisis de la crítica literaria" en términos de un cambio de episteme, espacio de orden, a partir del cual, ciertas "prácticas hegemónicas” o disciplinas de carácter ancilar terminan por perder su vigencia o al menos “ [...] que la lleva a revisar periódicamente, en una operación autorreflexiva, sus fundamentos, los límites de su supuesta autonomía, sus agendas y alianzas con campos afines, los vínculos que las unen a los niveles 'exteriores' que le brindan referencialidad, sentido histórico y valor ideológico" (2004: 192). Todo esto parece tener sentido en el contexto de los estudios culturales, la posmodernidad, la globalización y demás fenómenos que parecieran ser inéditos en sociedades como las latinoamericanas que, en términos económicos y políticos, nunca han dejado de ser definidas por el capitalismo periférico o dependiente y, por consiguiente, han tenido que hacerle frente a multiplicidad de fenómenos, a las discontinuidades y a las fragmentaciones de todo género y especie.

En consecuencia, dado el espíritu de los "nuevos tiempos”, la autora se propone hacer una descripción más o menos puntual del papel de la crítica literaria en la constitución de los discursos hegemónicos del continente latinoamericano, así como cierta complicidad con el poder de una burgue- 
sía ilustrada que maquinó la constitución de una "cultura nacional". Sin entrar en muchos detalles, en este ensayo, párrafo tras párrafo, desplaza el objeto de la crítica literaria desde la concepción de canon, "belletrismo burgués", a la noción de cultura entendida como "oralidad, multilingüismo, el documentalismo, los productos culturales "heterogéneos" (182-183) que revelan las interconexiones entre diversos sistemas culturales", esto en el contexto de la perspectiva marxista abierta por José Carlos Mariátegui, haciendo acopio de nuevos objetos de estudio, tales como lo "fronterizo", el entrecruzamiento de discursos, hibridismo y ¿̇por qué no? "totalidades contradictorias", discursos y sujetos migrantes como fenómenos propios de realidades culturales latinoamericanas ignoradas por la hegemonía del liberalismo burgués. En este sentido, en "Literatura, subjetividad y estudios culturales", al hablar de la diseminación de los estudios culturales anglosajones en América Latina, resalta la necesidad de interrogarse sobre el lugar de la subjetividad. Es así como empieza a indagar el papel de los estudios literarios en la hipotética redistribución de saberes planteada por los estudios culturales. En consecuencia, afirma Moraña:

La articulación literatura/subjetividad, mediada por el dispositivo ambiguo y desfasado del valor estético, se enfrentó desventajosamente a los nuevos modelos de interpretación cultural y a los debates acerca del impacto de las distintas prácticas simbólicas en formaciones sociales singulares pero cada vez más determinadas por la presión de mercados globalizados (2004: 191).

Pareciera ser que en este contexto "babélico", la literatura cambiara de estatuto y pasara de ser "el espacio privilegiado de la expresión de la individualidad burguesa, casi que irrestrictamente identitaria de los sectores dominantes" a transformarse en el espacio de formación y (auto) representación de sujetos colectivos. En este sentido, para Moraña, el conjunto de las obras denominadas literaturas nacionales o literaturas latinoamericanas o hispanoamericanas se han construido sobre las bases del "individualismo, interioridad, espacio privado y hedonismo burgués” en aras de la defensa de la subjetividad en cuanto invento burgués y al que los estudios literarios y la crítica misma deben su existencia. Es decir, la "subjetividad", la "literatura", la "crítica" y los "estudios literarios" no son más que un conjunto de aparatos y trampas ideológicas que, en el estado actual de las sociedades 
han perdido su poder de manipulación fuera de lugar en lo que denomina "ambiguo panorama ideológico del culturalismo posmoderno".

Paso seguido se refiere a Beatriz Sarlo y el texto comentado arriba de la siguiente forma:

\begin{abstract}
Algunos embates particulares, como el de Beatriz Sarlo ("Los estudios culturales..."), por ejemplo, no dieron resultado contundente, quizá porque la pregunta inicial ("¿Qué vuelve a un discurso socialmente significativo?”) no encontró, en su propio artículo, respuesta convincente, y el reclamo final (no dejar a la burguesía conservadora el placer y el monopolio de lo estético), al no partir de un análisis afinado de los procesos que anteceden a la actual compartimentación del conocimiento, transmitía un revanchismo sectorial de poco peso en la actual situación política y social de América Latina (Moraña, 2004: 192 ).
\end{abstract}

Después de esta interpretación, por demás un poco malintencionada, sobre todo en lo relacionado con la lectura parcial que hace de los niveles pragmáticos e interpelativos de la pregunta inicial -sobre lo que hace socialmente significativo a un discurso-, cree encontrar la respuesta a la pregunta en cuestión. Para Moraña, todo está dirigido a reiterar "la cualidad aurática de la literatura" que, aunque parezca imposible, considera el fundamento de una crítica literaria que, para ella, ha permanecido intacta desde el siglo XVIII en el contexto de la polémica entre antiguos y modernos. Salvo otra posibilidad, la autora ironiza el papel de los estudios literarios y de la crítica argumentando que la literatura, en cuanto artefacto cultural, política e ideológicamente hegemónico, se sustenta en el uso de imaginarios preservados y transmitidos culturalmente sin ninguna modificación, tercamente ahistórica, lo que explicaría para ella su perdurabilidad en el tiempo.

Esta postura, por demás muy distante de los estudios literarios actuales, no hace más que ignorar lo planteado por Walter Benjamin (2005) en relación con la "tensión entre el presente y el pasado, es decir, entre la crítica y la historia de la literatura” (25). Para este autor, emblemático de los estudios culturales, la historia de la literatura y la crítica literaria no son sólo dos ramas de los estudios literarios sino dos partes de una misma disciplina. En general, afirma, en relación con la historia de la literatura y su relación con la crítica: 
[...] no se trata de presentar a las obras literarias dentro del contexto de su tiempo, sino más bien de mostrar, dentro del tiempo en el cual ellas han nacido, el tiempo que ahora toma conocimiento de ellas, es decir, nuestro propio tiempo. La literatura debería, de este modo, ser una suerte de organon de la historia, y darle este lugar -en lugar de hacer de lo escrito un simple material para la historiografía- tal es realmente de la historia literaria (2005: 26).

Es evidente que la preocupación de Moraña se centra en la aparente imposibilidad que tienen los estudios literarios de explicitar "críticamente" los sistemas de sentido que, desde la perspectiva del momento de producción de las obras, se van modificando a tal punto que posibilitan su adecuación a la diversidad de funciones y concepciones de lo literario para las que no fueron concebidas y que incluso pueden llegar a contradecir. Si seguimos a pie juntillas lo planteado por Moraña, El Quijote no admite más lectura que la de la crítica a las novelas de caballería que tanto gustaban al público del siglo XVII, pero que ahora solamente se estudian en las universidades.

Sin ir más lejos, en párrafos posteriores parece que Mabel Moraña no está en contra de los "objetos auráticos" sobre todo en lo relacionado con un "afuera de la circulación permanente de la mercancía", junto con la permanencia de espacios simbólicos en los que, en palabras de la autora, "la opacidad representacional admite la conflictividad de memorias múltiples, expone transposiciones simbólicas entre diversos sistemas y agendas culturales, y deja en evidencia la porosidad y mutabilidad de los imaginarios" (2004: 193). En consecuencia, propugna por la separación de la literatura con el supuesto "valor de verdad" que dice ser afirmado por Sarlo y defiende el papel que tendría de facilitar identificaciones.

Moraña es enfática al afirmar que "el desafío de los nuevos tiempos exige una revalorización del discurso literario como una de las formas simbólicas y representacionales que se interconectan en la trama social, sin llegar a adjudicarle por eso un privilegio epistemológico - no a este ni a otras formas representacionales que, serán a su vez, opacas, ideológicas, contradictoria, polivalentes" (193). En términos generales para la autora: "[...] hemos entrado al debate necesario sobre la vigencia y reformulación de la crítica literaria por una puerta falsa" (193).

Para no alargar más la presentación de este documento, esta última afirmación y muchas de las transcritas en los párrafos anteriores parecen 
centrarse en el problema de la relevancia de unos discursos sociales sobre otros e incluso la desaparición de muchos de ellos en la obra literaria. ¿Por qué la literatura (aurática) debería estar por encima de otras producciones discursivas (orales, escritas, multimediales), cuando en todas ellas es susceptible la lectura de interacciones sociales simbólicas, ficticias, utópicas y alegóricas? (Moraña, 2004: 193-194).

En el artículo "Globalización académica, estudios culturales y crítica latinoamericana” (2001) de Nelly Richard, citado arriba, si bien comparte muchas de lo que ella denomina "[...] sospechas de la crítica latinoamericana en relación con los estudios culturales [...]", en cuanto teoría traspuesta, se adelanta a afirmar que " [...] la relación entre las localidades geoculturales (Estados Unidos y Latinoamérica) [...] no es una relación, dada, natural y fija, sino construida y mediada", es decir, "deconstruible y rearticulable" debido, entre otras cosas, por la diversidad de prácticas que envuelve el nombre "Estudios culturales" (2001: 188). Sin embargo, en relación con el tema que nos ocupa, ¿̇es posible sostener una oposición entre los valores estéticos y los estudios culturales con el argumento de que la exploración de los primeros, irremediablemente, remite a una posición ideológica excluyente, hegemónica y reaccionaria? Con el ánimo de disolver esta dicotomía, la autora enfatiza el papel que tradicionalmente ha cumplido la crítica de la cultura como postura teórico-política en la crítica e historia literarias del continente:

Este es otro de los interesantes desafíos que plantea la discusión en torno a los estudios culturales en sus cruces polémicos con el trabajo de la crítica literaria. Creo, en todo caso, que hace falta replantear ese desafío desplazando la cuestión del "valor literario" (demasiado susceptible de interpretarse en clave de formalismo estético) a otra formulación que abra los textos al análisis de las luchas entre los diferentes sistemas de valoración sociales a través de los cuales las hegemonías culturales van modelando los significados y las representaciones de la literatura y de lo literario. La teoría y la crítica feministas nos han enseñado mucho sobre las batallas interpretativas que rodean esta hegemonización del valor, y hace falta tomarlas en cuenta para polemizar con la institucionalidad dominante o la mercantilización de lo cultural (2001: 193).

Asimismo, esta relación entre los estudios culturales y la crítica latinoamericana, "presenta una movilidad de intersecciones [...] que desho- 
mogeneiza la relación poder/conocimiento de cada bloque territorial y que puede ser recorrida multidireccionalmente, siempre y cuando no se pierda de vista la necesidad de una reflexión metacrítica que someta a vigilancia cada una de estas intersecciones del discurso" (Richard, 2001: 189 ).

\section{La crítica literaria y el cambio de régimen de conciencia intelectual en América Latina}

Contrario a lo que podría pensarse a partir de lo expuesto arriba, habría que enfatizar en dos aspectos: el primero tiene que ver con la concepción de la "estética" como preceptora. Es cierto que en diversas ocasiones ha sido utilizada no sólo para condenar expresiones estético-literarias extrañas a los patrones occidentales, en el mejor de los casos, sino para deslegitimar expresiones culturales bajo el pretexto del desconocimiento de la norma y/o el desparpajo del mal gusto. Sin embargo, si nos atenemos a lo expuesto por Jacques Rancière en el sentido en que “[...] 'Estética' no es el nombre de una disciplina: es el nombre de un régimen de identificación específica del arte. Los filósofos, a partir de Kant, tienen la tarea de pensar dicho régimen. Pero no lo han creado" (Rancière, 2011: 17), es posible desembocar en la postura de Terry Eagleton, tal como se cita en el epígrafe de este trabajo.

El estudioso inglés concibe la estética como "forma híbrida" a partir de la cual se revela la "estructura interna de la concreto" que si bien no se puede desligar de la "construcción de las formas ideológicas dominantes de la sociedad de clases moderna, así como, en realidad, de toda una nueva forma de subjetividad humana apropiada a ese orden social" (Eagleton, 2006), contradictoriamente, "lo estético proporciona un poderoso e inusual desafío y una alternativa a estas formas ideológicas dominantes, razón por la cual se revela como un fenómeno eminentemente contradictorio" (2006: 53).

En segundo lugar, está la aceptación del estudio de la denominada "alta literatura" no como fuentes privilegiadas de emancipación cultural sino como la "expresión de historicidad en la medida en que representa una clase de performatividad sociocultural", tal como lo ha manifestado Alberto Moreiras (1999: 8).

Esta encrucijada, la crítica literaria como instrumento de exclusión en 
cuanto el ejercicio metodológico de la estética literaria, centrado en el estudio de formas ideológicas dominantes, pero a la vez como la reveladora de alternativas de estas formas dominantes, ha sido objeto de reflexiones ampliamente documentadas por historiadores de la literatura y la crítica latinoamericana, en su conjunto.

Entre los estudiosos más relevantes con perspectiva diferentes se pueden mencionar a Antonio Candido, Roberto Schwarz y Silviano Santiago para el ámbito brasileño; en Hispanoamérica, vale resaltar los trabajos del cubano José Antonio Portuondo desde la década de 1940, en especial con La emancipación literaria de Hispanoamérica (1975), el colombiano Carlos Rincón con su obra El cambio actual de la noción de literatura y otros estudios de teoría y crítica latinoamericana (1978), Roberto Fernández Retamar, Antonio Cornejo Polar, además, de Hugo Achugar, Noé Jitrik, Françoise Perus, Rafael Gutiérrez Girardot, Ángel Rama, Julio Ortega, Julio Ramos, etc., muchos de ellos con trabajos publicados desde las décadas del sesenta y setenta, y a propósito de eventos académicos continentales sobre el tema realizados en Venezuela, Cuba, México y Brasil.

Asimismo, interesados en historiar un momento crucial en la historia de la crítica literaria del continente, la década del setenta, coinciden en denunciar, a partir de finales de la década del cuarenta, una crisis que ha sido descrita como un cambio del régimen de la conciencia intelectual (Martínez, 1995: 39-64) o conjunto de "alteraciones ocurridas en el plano de la infraestructura de la producción intelectual" (Martínez, 1991: 15), cuyas magnitudes parecen extenderse a todo el ámbito cultural, político e ideológico del continente. Para este tema, son de vital importancia los trabajos del venezolano Agustín Martínez, entre los que se pueden destacar: Metacrítica. Problemas de historia de la crítica literaria en Hispanoamérica y Brasil (1995), Crítica y cultura en América Latina (1991) y el texto de Carlos Rincón, mencionado arriba. No obstante, la crisis se planteaba como efecto de la revitalización e "ingreso a la modernidad" de la literatura latinoamericana y la aparente incapacidad de la crítica literaria de dar cuenta de estos cambios, incluida la aparición de especializaciones profesionales y su ingreso al ámbito universitario.

En la actualidad, el desplazamiento de la literatura y en general de las humanidades como espacios de articulación de la ideología, el poder y la nación en el imaginario cultural y político del continente, lesiona gra- 
vemente el lugar y la función de los intelectuales cuya labor histórica ha sido interpretar dicha relación (Richard, 2001). A parte de esto, o tal vez por ello, en el contexto de los estudios culturales, la denominada crisis de lo literario abarca la ampliación del corpus y la reivindicación de nuevas formas de legitimidad de la crítica, tendientes a la ampliación del canon literario incluyendo expresiones culturales marginales, subalternas y desvalorizadas, lo que para Richard "disolvió lo estético en la masa de un sociologismo cultural" (192), más interesado en mostrar lo antihegemónico que las maniobras textuales de su voluntad de forma (Richard, 2001).

Los problemas que nos ocupan, en el fondo, son: ¿Cómo no caer en la suspensión de "juicio estético" cediendo terreno al sociologismo? y ¿Es posible hacer esta defensa de la crítica sin caer en el conservadurismo, al sustentar la universalidad y la trascendencia del juicio valorativo en defensa de la integridad del sistema literario; pero esta vez a la luz de los logros obtenidos en la luchas emancipatorias?

\section{A modo de cierre}

Una vez más, la crisis documentada por los teóricos literarios de la década del sesenta y setenta, en relación con la década del cincuenta, puede ayudar a imaginar unas posibles soluciones. Es así como el ingreso de diversas teorías metodológicas y literarias, tales como el formalismo, el marxismo y el estructuralismo, tras la clara escisión de la crítica en periodística y universitaria, aparentemente, efectuó una ruptura con cierta tradición de la crítica literaria continental. Sin embargo, tal como lo documentan Agustín Martínez y Carlos Rincón, por mencionar tan sólo algunos, en lo que respecta al primero, desde un punto de vista superficial, la recepción de nuevas tendencias críticas lejos de ser una "pueril imitación de los modelos importados" dando origen a lo que el autor denomina una "trivialización" del discurso crítico (Martínez, 1995: 83), permitió que se efectuara una modernización de la disciplina y, en consecuencia, el planteamiento de nuevos problemas relativos a la literatura continental aparecida desde la década del treinta, pero que tiene sus manifestaciones más claras en el denominado boom de la literatura latinoamericana en la década del sesenta.

La crítica en sí misma, como parte del ámbito cultural y una de las ex- 
presiones privilegiadas del régimen de conciencia intelectual, adelantó con el paso del tiempo un proceso de "intenso intercambio entre las perspectivas aportadas por las nuevas estéticas y las líneas maestras que rigen el comportamiento intelectual y, consiguientemente, las respectivas tradiciones críticas en Hispanoamérica y el Brasil" (Martínez, 1991: 25). En estas tradiciones, citando lo propuesto por Alejandro Losada Guido, en "Discursos críticos y proyectos sociales en Hispanoamérica" (1975), Martínez identifica "las siguientes actitudes: el positivismo historicista y erudito (Ricardo Rojas, Luis Alberto Sánchez), la interpretación impresionista y subjetivista (Mariátegui, Rivas Agüero, Martínez Estrada) y el humanismo cultural (Rodó, Henríquez Ureña, Alfonso Reyes)". Tentativas que se "resuelven en tres tendencias predominantes que se encuentran fuertemente influidas por otras tantas europeas: el formalismo neo-positivista, el idealismo positivista y el marxismo" (Martínez, 1995: 53-54).

En términos generales, la crítica literaria continental ha pasado por diversos momentos de crisis superados, tal debe ser el caso de la irrupción de los estudios culturales. Sin embargo, una vez terminado el proceso de asimilación debe retomar, aún más fortalecida por ellos, el lugar que le ha correspondido no sólo en lo concerniente a la evaluación de obras literarias que, de por sí es una labor importante para cualquier sociedad, sino su papel configurador de espacios discursivos e intelectuales entendidos como expresiones de una evaluación o revelación de la obra entendida como inacabada e informe, en términos de Pierre Macherey:

Explicar la obra es, en lugar de remontarse hasta un centro escondido que le daría vida (la ilusión interpretativa es organicista y vitalista), verla en su descentramiento efectivo; es pues negar el principio de un análisis intrínseco (o de una crítica inmanente) que cerraría artificialmente la obra sobre sí misma; y por el hecho de que es entera, deduciría la imagen de una "totalidad" (porque las imágenes también se deducen). La estructura de la obra, que permite rendir cuenta de ella, es ese desajuste interno, o esa cesura, por cuyo medio corresponde a una realidad, también incompleta, que deja ver sin reflejarla. La obra literaria ofrece la medida de una diferencia, muestra una ausencia determinada: es la que dice si ella, por fuerza no habla mucho al respecto. Así, lo que debe verse en ella es lo que le falta, una carencia sin la cual no existiría, sin la cual no tendría nada que decir, ni los medios de decirlo o de no decirlo (1974: 81). 
Desde esta perspectiva, la literatura en general es objeto de un acto de explicación actualizador, como parte de la función de la crítica literaria. La construcción de puentes entre este pasado, el presente y el futuro desde el punto de vista benjaminiano de lo histórico como el acallado proyecto político tras la aparente continuidad del discurso pedagógico. Es así como la crítica no es solamente una metodología de lecturas histórico-literarias y el esfuerzo interpretativo del presente, sino un campo discursivo disciplinar en el que la textualidad pasa a convertirse en un aspecto central de la construcción de sentidos.

\section{Referencias}

Achugar, H. (1998). Leones, cazadores e historiadores. A propósito de las políticas de la memoria y del conocimiento. En Castro-Gómez, S. y Mendieta, E. (eds.), Teorías sin disciplina. Latinoamericanismo, poscolonialidad y globalización en debate. Disponible en http://people.duke.edu/ wmignolo/ InteractiveCV/Publications/Teoriassindisciplina.pdf

Benjamín, W. (2005). Historia literaria y ciencia de la literatura. Contrahistoria. La otra mirada de Clío, 3, 21-26.

Beverly, J. (1996). Estudios culturales y vocación política. Revista de Crítica Cultural, 12. Disponible en http://www.ram-wan.net/restrepo/introeeccs/11.1.eeccs\%20y\%20vocacion\%2opolitica-beverley.pdf

Casanova, P. (2001). La República mundial de las letras. Barcelona: Editorial Anagrama.

Castro-Gómez, S. (2003). Apogeo y decadencia de la teoría tradicional. Una visión desde los intersticios. En Walsh, C. (ed.), Estudios culturales latinoamericanos. Retos desde y sobre la región andina (pp. 59-72). Quito: Universidad Andina Simón Bolívar-Abya-Yala.

(2008). Althusser, los estudios culturales y el concepto de ideología. Disponible en http://www.oei.es/salactsi/castro3.htm

Green, M. (1997). Ideología. Una introducción. Barcelona: Paidós.

Eagleton, T. (2006). La estética como ideología. Madrid: Editorial Trotta. (2008). Estudios culturales (cultural studies). En Payne, M. (comp.), Diccionario de teoría crítica y estudios culturales. Buenos Aires: Paidós.

Hall, S. (1994). Estudios culturales: dos paradigmas. Disponible en http:// www.biblioteca.org.ar/libros/131827.pdf

Macherey, P. (1974). Para una teoría de la producción literaria. Caracas: Biblioteca de la Universidad Central de Venezuela. 
Martínez, A. (1991). Crítica y cultura en América Latina. Caracas: Fondo Editorial Tropycos.

(1995). Metacrítica. Problemas de la historia de la crítica literaria en Hispanoamérica y Brasil. Mérida: Universidad de los Andes.

Mattelart A.-Neveu, E. (2004). Introdução aos Estudos Culturais. São Paulo: Parábola Editorial.

Mignolo, W. (2003). Las humanidades y los estudios culturales: proyectos intelectuales y exigencias institucionales. En Walsh, C. (ed.), Estudios culturales latinoamericanos. Retos desde y sobre la región andina (pp. 31-57). Quito: Universidad Andina-Abya-Yala.

Mojica de, S. (2000). Culturas híbridas-No simultaneidad-Modernidad periférica. Mapas culturales para América Latina. Verlag Berlín: Wiss.

Moraña, M. (2004). Crítica impura. Estudios de literatura y cultura latinoamericana. Madrid: Iberoamericana-Vervuert.

Moreiras, A. (1999). Tercer espacio y duelo en América Latina. Santiago: Escuela de Filosofía de la Universidad de Arcis.

Perus, F. (2009). Leer no es consumir. La literatura latinoamericana ante la globalización. Revista de Crítica Literaria Latinoamericana, 69, 11-31.

Rancière, J. (2011). El malestar en la estética. Buenos Aires: Capital Intelectual.

Richard, N. (2001). Globalización académica, estudios culturales y crítica latinoamericana. Cultura, política y sociedad. Perspectivas latinoamericanas. (pp. 185-199). Buenos Aires: CLACSO.

(2010). Respuesta a un cuestionario: posiciones y situaciones. En Entorno a los estudios culturales. Localidades, trayectorias, disputas (pp. 6783). Santiago: CLACSO-Editorial Arcis.

Rojo, G. (2012). De las más altas cumbres. Teoría crítica latinoamericana moderna (1876-2006). Santiago: Lom Ediciones.

Said, E. (2008). El mundo, el texto y el crítico. Barcelona: DeBolsillo.

Sarlo, B. (1992). La imaginación técnica. Escenas de la vida posmoderna. Intelectuales, arte y videocultura en Argentina. Buenos Aires: Ariel. (1997). Ensayos argentinos de Sarmiento a la vanguardia. Buenos Aires: Ariel.

(2000). Los estudios culturales y la crítica literaria en la encrucijada valorativa. En Sarlo, B.; Schwarz, R. y Kraniauskas, J. (eds.), Culturas híbridas-No simultaneidad-Modernidad periférica. Mapas culturales para la América Latina (pp. 231-240). Verlag, Berlin: Wiss.

Sarlo, B.; Schwarz, R. y Kraniauskas, J. (eds.). (2000). Literatura y valor. En Culturas híbridas-No simultaneidad-Modernidad periférica. Mapas culturales para América Latina. Verlag Berlin: Wiss.

Szurmuk, M. y McKee, I. R. (2009). Diccionario de estudios culturales latinoamericanos. México: Siglo XXI-Instituto Mora. 